\title{
Democratización de las identidades, transgenerismo y malestares de género
}

FERNANDO FDEZ-LLEBREZ*

\begin{abstract}
Artículo recibido: $1^{\circ}$ de octubre de 2014
Artículo aprobado: 11 de marzo de 2015

Doi: dx.doi.org/10.12804/desafios27.2.2015.03

Para citar este artículo: Fdez-Llebrez, F. (2015). Democratización de las identidades, transgenerismo y malestares de género. Desafíos, 27(II), pp. 99-143. Doi: dx.doi.org/10.12804/ desafios27.2.2015.03
\end{abstract}

\section{Resumen}

Elpropósito del presente articulo es estudiar la relación o relaciones que se dan entre la formación y la definición de las identidades (individuales y colectivas) y el desarrollo de una ciudadanía democrática, para lo cual se tomará como ejemplo concreto el análisis de las identidades sexuales y de género. En este sentido, se pretende demostrar que, para que se pueda dar una democratización de estas identidades, es preciso abandonar la concepción dicotómica que las caracteriza y desplegar una consideración de estas como realidades fluidas accesibles para toda la ciudadanía democrática en la que las aportaciones teóricas del transgenerismo pueden ser útiles para pensar de manera más inclusiva nuestra vida.

Palabras clave: identidad, ciudadanía, democracia, género, transgenerismo.

\footnotetext{
* Profesor titular del Departamento de Ciencia Política y de la Administración, Univer-
} sidad de Granada (España). Correo electrónico: fernando@ugr.es 


\title{
Democratization of Identities, Transgender and Gender Discomfort
}

\begin{abstract}
The purpose of this paper is to study the relationship that exists between training and the definition of identities (individual and collective) and the development of a democratic citizenship, which is taken as an example of the analysis of sexual and gender identities. The article aims to demonstrate that for a democratization of these identities one must leave behind the dichotomous conception that characterizes them and instead deploy a consideration of them as accessible, fluid realities for all democratic citizenship in which the theoretical contributions provided by transgenderism may be useful to think more inclusively about our lives.
\end{abstract}

Keywords: identity, citizenship, democracy, gender, transgenderism.

\section{Democratização das identidades, transgenerismo e mal-estares de género}

\begin{abstract}
Resumo
O propósito do presente artigo é estudar a relação ou relações que se dão entre a formação e a definição das identidades (individuais e coletivas) e o desenvolvimento de uma cidadania democrática, para o qual apresentara-se como exemplo concreto a análise das identidades sexuais e de gênero. Neste sentido, pretende-se demostrar que, para que se possa se dar uma democratização destas identidades, é preciso abandonar a concepção dicotómica que as caracteriza e desenvolver uma consideração destas como realidades fuidas accessiveis para toda a cidadania democrática na que as contribuições teóricas do transgenerismo podem ser úteis para pensar de forma mais inclusiva nossa vida.
\end{abstract}

Palavras-chave: identidade, cidadania, democracia, gênero, transgenerismo. 
"Un deseo salvaje ha fluido de mi corazón a mi cabeza y no lo reprimiré aunque pueda excitar carcajadas. Deseo honestamente ver cómo la distinción de los sexos se confunde en la sociedad".

Wollstonecraft (1994, p. 185)

\section{Introducción. Planteamiento del problema}

Debatir y reflexionar sobre la teoría de la democracia y su práctica es uno de los asuntos más relevantes en la teoría política contemporánea (Dahl, 1992). Son muchas las revistas de gran prestigio que dedican páginas a este menester y aún son más los trabajos que hay escritos sobre ello. Por eso, es preciso delimitar bien el objeto de este trabajo para así denotar cuál es su aportación singular dentro del actual periplo científico político.

De manera sintética se puede afirmar que el objeto del presente artículo es estudiar y analizar la relación o relaciones que se dan entre la formación y la definición de las identidades (individuales y colectivas) y el desarrollo y la forja de una ciudadanía democrática. Como es bien sabido, este objeto de estudio no es nuevo en la teoría política contemporánea, aunque será el enfoque desde el que se abordará lo que aportará su novedad más significativa, así como algunas de las conclusiones a las que se llega.

La tesis central que se defenderá en las páginas siguientes será que, si se pretende democratizar la ciudadanía, es preciso democratizar las identidades, para lo cual es necesario una reformulación teórica de dicha categoría. El propósito de esta tesis es lo suficientemente general como para que sea oportuno centrar tal cuestión en algún tipo de identidad concreta que nos permita hacer ese recorrido de forma clara y precisa. Para ello, acotaremos nuestro objeto de trabajo al estudio de las identidades sexuales y de género, siendo estas un buen ejemplo del necesario proceso democratizador que nuestras democracias requieren.

Para alcanzar dicho objetivo, se intentará validar teóricamente la siguiente hipótesis de trabajo: para que se pueda dar una democra- 
tización de las identidades de género, es preciso abandonar la concepción dicotómica que las caracteriza y desplegar una consideración de estas como realidades fluidas accesibles para toda la ciudadanía democrática en la que las aportaciones teóricas del transgenerismo pueden ser útiles para pensar de manera más inclusiva nuestra vida.

El contraste de tal hipótesis supone analizar diferentes variables que interactúan entre sí. La primera de ellas tiene como propósito llevar a cabo un recorrido por la concepción hegemónica en los estudios sobre las identidades de género, la cual se debe insertar en una concepción más amplia sobre las identidades. A esta concepción más extensa la hemos denominado los mitos de la identidad y es una que pretende hacer una definición de esta desde unos parámetros metafísicos y ontológicos determinados. La cuestión será comprobar en qué medida dichos mitos son reproducidos a la hora de estudiar las identidades sexuales de género, de tal modo que su perspectiva hegemónica supone la reproducción de estos. La función de esta variable es constatar la presencia teórica de tal tesis en la literatura especializada para así poder mostrar sus fallas a lo largo del trabajo, y ocupará los tres apartados siguientes del artículo (en concreto los numerados como 3, 4 y 5).

La segunda tiene que ver con por qué dicha teoría sobre las identidades muestra fallos de carácter teórico al dar por supuestos unos dilemas que no están en la realidad, sino en su propia preconfiguración dogmática. La consecuencia política de este dogmatismo será la exclusión de la parte de la sociedad que no se sienta reflejada en esa teoría. Estos huecos e inconsistencias nos ocuparán los apartados 6 y 7 del artículo, y nos llevarán a preguntarnos por la necesidad de buscar otra teoría que sí sea capaz de cumplir el requisito democrático de la inclusión ciudadana como eje motor de su definición. Este propósito nos conducirá a la tercera variable en cuestión referida a cómo la reflexión teórica del transgenerismo sí es una buena forma de definir nuestras identidades, pues, al romper con los mitos anteriormente señalados, permite integrar al conjunto de la ciudadanía a través de un continuum inclusivo en donde nadie es expulsado por tener una u otra identidad, de tal modo que el acuerdo democrático viene dado por la defensa, 
no de una misma forma de sentirse, sino por los valores de libertad e igualdad que caracterizan a la democracia; de ahí que sea oportuno hablar de una democratización de las identidades como mecanismo político para solventar la falla descubierta en los primeros epígrafes del presente trabajo. Este recorrido nos tomará los apartados 8 y 9 , y, por último, se indicarán las conclusiones del trabajo.

\section{Los mitos de la identidad y su problematización democrática}

La aproximación teórica sobre la democracia se ha caracterizado mayoritariamente por centrar los debates en sus aspectos más institucionales. Ha sido el debate sobre si tal o cual institución es verdaderamente democrática — pregunta ya en sí complicada de resolver-o si tal o cual institución debe modificarse en aras de una mayor democracia la perspectiva desde la que la teoría política normativa más veces se ha aproximado a esta cuestión. También ha habido toda una serie de estudios, más centrados en la historia de la teoría política, que han reflexionado sobre las distintas tradiciones de discurso que conforman dicha experiencia. ${ }^{1}$

En los estudios empíricos, también la democracia ha tenido notable predicamento. Lo ha tenido para hacer ciertas loas de esta en un sentido economicista y tecnocrático. ${ }^{2}$ Pero la más de las veces ha habido otros enfoques que han intentado incorporar elementos que vayan más allá de la versión institucional. La dimensión característica, aunque no la única ${ }^{3}$ que se suele señalar para ello, ha sido la referida a la cultura política; y lo ha sido unas veces para criticar ciertos modelos de cultura política y otras para afianzar el modelo tradicional. ${ }^{4}$

Los estudios más osados y contemporáneos han sido aquellos que, desde la ciencia política en consonancia con los estudios históricos y

\footnotetext{
1 Para el concepto de tradición de discurso, ver Wolin (1974, pp. 11 y ss.).

2 Ver, respectivamente, Downs (1967) y Schumpeter (1984).

3 Para un recorrido básico sobre los distintos approaches, ver Roiz (1980).

4 Desde la primera perspectiva, destaca la obra de Inglehart y Welzel (2006); y, en la segunda y más tradicional, el clásico de Almond y Verba (1963).
} 
la historia del pensamiento político, han planteado una aproximación a la democracia como un proceso amplio, rico y variado en el que intervienen diferentes factores que conforman una realidad compleja y procesual. ${ }^{5}$ En este sentido, se ha manifestado que una democracia es la interacción de los siguientes elementos. Por un lado, desde el punto de vista político institucional, el entreveramiento entre un estado de derecho (imperio de la ley), cierta participación ciudadana (derechos políticos) y una determinada cohesión social (derechos sociales), con los respectivos intermediarios ya altamente institucionalizados que lo caracterizan (partidos políticos y sindicatos). Por otro lado, estaría la sociedad civil con tres espacios de participación independientes e interconectados entre sí: los movimientos sociales, las asociaciones civiles y el ciudadano o ciudadana individual. Es en la interacción entre la política institucional y la sociedad civil en donde se erige y forja el concepto de espacio público como lugar en el que la democracia cobra su génesis más característica. ${ }^{6}$

Todas estas 'aproximaciones teóricas', ya sean más institucionalistas o procesuales, han dado y seguirán dando grandes aportaciones a la teoría democrática actual, así como a su configuración histórica. Y, como tales, son necesarias e imprescindibles para una comprensión adecuada de la democracia y de sus retos contemporáneos. No obstante, esto no quita para reconocer que sigue habiendo una carencia importante - señalada por un planteamiento teórico proveniente del sur de Europa y que en el mundo académico (a falta de mejor palabra) podríamos denominar como tradición latina de la democracia- ${ }^{7}$ sobre uno de los elementos centrales de la teoría de la democracia. Su carencia es la escasa reflexión realizada sobre el ciudadano o ciudadana, no como portador de ciertos derechos (sobre lo cual sí se ha escrito y de manera excelente), sino como persona que se configura

\footnotetext{
5 En este abanico de autores, podemos citar, entre otros y pese a sus diferencias, a Skinner (1993), Tilly (2007) y Tarrow (2005). Del mismo modo, destacar los debates relativos a la cultura política y sus nuevos retos teóricos para la ciencia política y la historiografía. Para un recorrido por esta literatura y con atención al caso español, ver Pérez Ledesma y Sierra (2010).

6 Para una aproximación más detallada a esta definición, ver Fdez-Llebrez (2014).

7 El autor de referencia para ello es, entre otros, Javier Roiz. Ver Roiz (2013).
} 
en un espacio público-privado y en el que intervienen distintos elementos psicológicos en su quehacer cívico. Es una forma teórica de acercarse a la ciudadanía en la que se atiende tanto su letargia como su vigilia, ${ }^{8}$ entendiendo al ciudadano como un actor político que vive todos los días de su vida, que habita en distintos ambientes (trabajo, hogar, filiación social y/o política,...), que se despierta y duerme, y que se relaciona con otros individuos y grupos.

Esta dimensión cívica ha sido tratada, algunas veces, a través del concepto de identidad, por eso han sido las teorías feministas o las relativas a la multiculturalidad las que más se han adentrado en dicha dimensión, pero, aun así, con ciertas limitaciones. Dos de las carencias o limitaciones teórico-políticas más relevantes que estos planteamientos han mostrado son las siguientes.

La primera remite a que la gran parte de las teorías feministas y/o multiculturalistas se han desarrollado como explicaciones ajenas a la teoría política democrática, de tal modo que afectaba a cuestiones que 'solo interesaban' al grupo correspondiente estudiado (mujeres, negros,...), y no como categorías analíticas relacionadas con el sentido general de la ciudadanía democrática. ${ }^{9}$ En este artículo, se defenderá una tesis contraria para la cual la identidad como categoría teórica debe ser conceptualizada de tal modo que sí queden relacionadas con el sentido transversal de la ciudadanía democrática, afectando no solo a una parte, sino al conjunto de la sociedad, por lo que su democratización es crucial para su éxito cívico.

La segunda carencia afecta a la forma en la que se define la identidad; una perspectiva reduccionista que no entiende que haya "una parte de la identidad humana, de cada ser humano, en la que no funciona el principio de identidad" (Roiz, 2013, p. 28). Este no es un debate de carácter lógico-formal ni sobre el lenguaje ordinario (Austin, 1991),

\footnotetext{
8 Ver Roiz (2013).

9 En este trabajo, señalaremos algunas excepciones en el terreno feminista, como son Nancy Fraser, Seyla Benhabib o Amy Gutmann. Para el caso español, la autora de referencia es Cristina Garaizabal.
} 
sino ontológico-filosófico, en el sentido de qué es lo que constituye la estructura psíquica de un(a) ciudadano(a). De este modo, la no identificación entre principio de identidad e identidad supone llevar a cabo "una redefinición radical del individuo" (Roiz, 2013, p. 29) y problematizar tres mitos filosóficos bastante asentados en las doctrinas imperantes.

a) El mito metafísico esencialista. ${ }^{10}$ Según este mito, a cada entidad (o ente) le corresponde unos y solo unos atributos determinados y no otros, de tal manera que el conflicto entre atributos es interpretado siempre como una contradicción. Así, las categorías hombre y mujer se encuentran en contradicción entre sí hasta el punto de que la negación de uno siempre supone la afirmación del otro, no habiendo caminos intermedios. ${ }^{11}$ La ruptura con dicho mito supone aceptar que los términos hombre y mujer pueden ser diferentes, pero no son contradictorios entre sí, siendo factibles toda una serie de identidades intermedias. ${ }^{12}$

b) El mito cartesiano. Para este mito, las personas nos constituimos ontológicamente a través de pares disyuntivos apriorísticos, tales como mente/cuerpo, interno/externo, público/privado, accesible/ inaccesible, etcétera (Descartes, 1983). ${ }^{13}$ Unas disyuntivas que se trasladan a la vida política y democrática mecánicamente de tal manera que las identidades políticas o son polarizantes y están polarizadas o no es posible la identidad. Un ejemplo de ello lo encontramos en los postulados nacionalistas que obligan a optar por una identidad cultural (o nacional) como eje vertebrador e

\footnotetext{
10 De origen griego o, para ser más exactos, platónico-aristotélico. Son inmensas las obras que hacen esa lectura griega en la tradición política occidental — por ejemplo, Calvo Martínez (2011)-.

11 El ejemplo paradigmático de este razonar está en el feminismo cultural de los ochenta sobre el que nos detendremos más adelante.

12 Así, se puede ser 'hombre' con atributos categorizados como masculinos y femeninos, y también se puede ser hombre, mujer, transexual, (...).

13 Una de las primeras críticas a este mito la tenemos en la obra del sefardí Baruch Spinoza.
} 
ineludible de su quehacer político, imposibilitando (o dificultando sobre manera) formas de identificación más complejas. ${ }^{14}$

c) El mito del yo volitivo de carácter romántico. ${ }^{15}$ Este mito es deudor del anterior y postula la existencia de un yo ontológico (o un nosotros que actúa como un yo) que gobierna nuestras vidas cual emperador triunfante. Es un yo ontológico volitivo inescrutable, que es analizado como una especie de "fantasma" (Ryle, 2005, p. 32), quien guía siempre al conjunto de nuestra identidad hasta el punto de equiparar la identidad con el yo, ${ }^{16}$ subsumiendo aquella en este. La problematización de este tercer mito no supone negar que haya acciones voluntarias e involuntarias, sino más bien reconocer que la vida común y ordinaria de los ciudadanos es una realidad más compleja, rica, entreverada y, a la vez, sencilla. No reconocer esta complejidad del ser humano supone situar la omnipotencia en el centro de la democracia; de ahí que la forma de control ideada sea algún tipo de tiranía ante ese hipotético desbocado yo.

La consecuencia política de la identificación entre principio de identidad e identidad ha sido la expulsión normativa y efectiva, sobre todo en el espacio público, de aquellas identidades que no encajan satisfactoriamente en dicha identificación.

La crítica a las dos carencias señaladas (la primera de carácter más teórico y la segunda más política) alimenta la idea de la necesidad de democratizar las identidades de los ciudadanos y ciudadanas como uno de los ejes de cambio de nuestras actuales democracias; democratización que autores como Javier Roiz o Sheldon Wolin han planteado recientemente en sus obras. ${ }^{17}$ En nuestro caso, haremos esa aproximación

\footnotetext{
14 Es verdad que toda categoría política, en el terreno material, contiene cierta forma de exclusión. Pero el problema no está en esa limitación material ineludible, sino en si las categorías se han confeccionado de tal modo que la fluidez y el movimiento quedan incorporados o, por el contrario, aparcados, ya que ni pueden ni deben caber.

15 El representante mayor de esta concepción sería Johann G. Fichte. Ver Fichte (1994).

16 O la 'voluntad' en el sentido romántico del término. Ver Fichte (1994).

17 La expresión que usa Sheldon Wolin es "democratización del self” (2008a, p. 289). La obra teórico-política de Roiz está plagada de referencias a esa misma categoría, incluso antes
} 
tirando del hilo del feminismo, aunque se podría hacer tomando en cuenta otras identidades, pese a que no son meramente intercambiables.

\section{La crítica a las 'políticas de identidad'}

En la literatura habitual de la teoría política contemporánea, las políticas de identidad suelen tener su justificación a partir del reconocimiento de que hay relaciones de desigualdad, exclusión, marginación o negación que deben ser reformuladas en aras de una mayor o plena igualdad. Como señala una de sus defensoras, Iris Marion Young, sin esas relaciones asimétricas las políticas de identidad no tienen sentido político ni social, de ahí que queden vinculadas a alguna forma de definir la injusticia, la opresión, o conceptos de índole similar, que rompen la teórica neutralidad (Young, 1996, p. 111); una fractura que desvela la existencia de sujetos concretos y encarnados, entre los que emergen, por ejemplo, el varón de mediana edad, de clase media, blanco e instruido.

Ante esa realidad discriminatoria, la defensa de las politicas de identidad conlleva una serie de medidas que intentan paliar, o erradicar, dicha situación. Ejemplos de esto lo tenemos en las políticas de discriminación o afirmación positiva, en la exigencia de igualdad ante la ley, en las políticas de paridad y de atención sanitaria (SIDA), en la defensa del orgullo gay y del día de la mujer, etcétera. Como dice Diana Fuss en relación con la cuestión gay - aunque sería válido para otras problemáticas-: "Las políticas de identidad se han utilizado por parte de activistas gays como algo parecido a un grito de recomposición para estimular la conciencia personal y la acción política" (Fuss, 1990, p. 1), actuando, tales políticas, como 'políticas de afirmación' (Weeks, 1993, p. 294). Estas exigencias son realidades (y deseos) que fueron y siguen siendo necesarias para plantear la indeseable desigualdad existente hoy en día. En este sentido, consideramos que tales medidas son herramientas sociales y políticas todavía hoy legítimas ante las situaciones de exclusión e injusticia reinante, 
pese a que no son la única, ni a veces la mejor, forma de abordar dichas injusticias. ${ }^{18}$

En cualquier caso, no todas las políticas de identidad son defendidas de la misma manera. ${ }^{19}$ Como parece obvio, en todas las politicas de identidad, la propia cuestión de qué es la identidad ocupa un lugar significativo. Pero, a partir de esta idea general, se han elaborado diferentes formas de acercarse a ellas. Diferencias que vienen marcadas por el tipo de relación que se dé entre política e identidad.

Por un lado, están aquellas teorías sobre la identidad que podríamos denominar como culturalistas, que tienen como fundamento teórico "levantar una comunidad política cohesionada y visible" (Fuss, 1990, p. 1) en donde la conceptualización sobre qué es la identidad, y el lugar que ocupa en nuestra vidas, se convierte en el elemento causal que define el tipo de políticas de las que estamos hablando.

Esta concepción culturalista afecta a una pluralidad de pensadores y pensadoras. En el terreno feminista, la corriente denominada como feminismo cultura ${ }^{20}$ es la que, de forma paradigmática, mejor la representa. Pero también hay otras teóricas — dispares entre sí y alejadas de dicha corriente-, como Luce Irigaray, Barbara Smith o Audre Lorde $^{21}$ —entre otras-, que compartirán la idea de que tenemos una politica porque anteriormente tenemos una identidad. La propia Smith lo señala de forma contundente en el siguiente párrafo: "Como mujeres negras tenemos una identidad y, por lo tanto, una política que exige fe en la humanidad negra. Nos estamos oponiendo abiertamente a las concepciones de los hombres blancos de lo que es la humanidad y demostrando que no es una cuestión de ellos, sino de nosotras" (citado por Fuss, 1990, p. 3). De este modo, la política adecuada es

\footnotetext{
18 Para un recorrido por la historia de estas reivindicaciones, ver Sánchez (2001, pp. 17 y ss.).

19 Para una manera diferente a la defendida por Young, ver Benhabib (2006a) y Fraser (2000).

20 A este menester puede verse, entre otras autoras: Dworkin (1983) y Daly (1978). Para un excelente recorrido por el feminismo cultural: Osborne (1993).

21 Irigaray (1992); Hull, Scott y Smith (1982); y Lorde (2003).
} 
la consecuencia de una identidad que está previamente establecida y claramente asentada y definida. Es como si la identidad fuera algo que siempre ha estado allí y que lo único que nos queda es reconocerla tal y como se manifiesta, tal y como se expresa.

Por otro lado, se encuentran quienes, como Amy Gutmann, plantean justamente la cuestión de forma inversa. Para Gutmann, desde el punto de vista democrático, una política de identidad tiene su justificación en lo que públicamente trata de conseguir y expresar, y no en la existencia de una identidad predefinida (Gutmann, 2008, p. 271), por lo que la causalidad está en su dimensión política y no en la propia identidad. Un planteamiento que, en contraposición con el anterior, lo podríamos denominar como político o cívico.

Tirando de este hilo teórico, en el que se sitúan autoras feministas como la citada Gutmann, la arendtiana Seyla Benhabib, la pragmática Nancy Fraser e, incluso, la humanista Martha Nussbaum (cada una distinta de la otra, pero relacionadas entre sî), pretendemos discutir la perspectiva culturalista con la intención de saber si es la mejor forma de definir la identidad, y en concreto las referidas a los géneros y los sexos, y en qué medida este planteamiento esencializa la propia idea de identidad confundiendo conceptos como esencia e identidad. Si esto fuera así, entonces, se tornaría preciso reescribir y reteorizar el propio concepto de identidad, así como la relación que se establece entre democracia moderna e identidad, pudiéndose hablar, cuanto menos, de una relación bidireccional entre ambos conceptos.

Esta problematización de la identidad tiene como propósito buscar una mejor y más adecuada conceptualización de los procesos identitarios de género y de sexualidad en nuestras democracias. Pero no lo hace tratando de crear el modelo definitivo y auténtico de género como si este fuera la nueva sintesis dialéctica que pretende encontrar la solución final a todos los problemas (Roiz, 2003, pp. 13-64). Tal planteamiento choca con una perspectiva política y democrática de la identidad, como la nuestra, la cual está sujeta a las imperfecciones y contradicciones que la propia democracia contiene. Si la democracia es un planteamiento que se lleva mal con la omnipotencia (Fdez- 
Llebrez, 2001, pp. 46 y ss.), entonces, las identidades de género y sexo que se den en su seno no podrán ser perfectas ni totales, sino que se caracterizarán por ser dinámicas, complejas y fluidas. Y, si queremos que dichas identidades emerjan y florezcan, es preciso (es condición sine qua non) dotarse de un planteamiento teórico sobre dichas identidades que abra el campo de las posibilidades democráticas para que sea factible vivir de forma inclusiva nuestra vida con géneros.

Es cierto que esta concepción de las identidades queda vinculada a las exigencias normativas de las democracias modernas (libertad, igualdad, inclusión, pluralismo,...), excluyendo ciertos comportamientos que quedan fuera de tales exigencias. ${ }^{22}$ Pero también lo es que no tiene un afán normativizador ni vigilante en el sentido de definir, y perseguir, una única forma de ser hombre, mujer,... pues se concibe como un lugar para el reconocimiento y la redistribución identitaria en el que cabrán una variedad de formas de sentirnos, más allá de que a alguien le satisfaga más una que otra. En el fondo, esta manera de acercarnos a la identidad supone llevar a cabo el reto de democratizar las identidades como forma de ampliarlas y enriquecerlas. Una democratización de las identidades que, inspirada en criterios humanistas, ${ }^{23}$ permita el desarrollo de identidades menos excluyentes y, a la vez, alejadas del dogmatismo, para que así tengamos mayor capacidad para abordar la pluralidad y complejidad de nuestra vida con géneros en nuestras sociedades democráticas avanzadas.

Para llevar a cabo esta reflexión, tomaremos como punto de inflexión realidades identitarias ya existentes que, por ser consideradas como no normales, han sido y son estigmatizadas, pero que son, sin embargo, tan reales como la vida misma y con la misma legitimidad que las comúnmente reconocidas. Nos referimos a las posibilidades que abren

22 Por ejemplo, y entre otros, aquellos que supongan la negación del otro.

23 El vocablo humanista es polivalente. En nuestro caso, remite al humanismo retórico de origen grecolatino. Entre sus autores clásicos, podemos destacar a Marco F. Quintiliano, Nicolás Maquiavelo, Giambattista Vico,... Y, más recientemente, a Hannah Arendt, Quentin Skinner, Javier Roiz, Sheldon Wolin, la sefardí Seyla Benhabib,... Para un recorrido por dicha tradición, ver Alonso (2010). Sin formar parte de esta tradición, pero con un humanismo de influencias senequistas y ciceronianas, ver Nussbaum (2005). 
los y las transexuales (y los drag queen) (Butler, 1999, pp. 10 y ss. y 174 y ss.) tanto para ellos y ellas mismas como para el conjunto de las personas con género (sea este el que sea). Todo un reto para el siglo XXI.

Y, por último, nos aproximaremos a dicha reflexión desde un pensamiento feminista ${ }^{24}$ que se tomará en serio una de las afirmaciones feministas más característica, como fue la realizada por Simone de Beauvoir en relación con que la mujer no nace, sino que se hace (De Beauvoir, 1999), y que puede y debe ser extensible también a los hombres.

\section{El difícil ajuste entre identidades colectivas e individuales}

Por lo menos desde la modernidad en adelante, y sobre todo desde mediados del siglo XIX, las identidades, ya sean individuales y/o colectivas, se caracterizan por una serie de rasgos. De los variados factores que las definen, destacaremos los dos siguientes.

Por un lado, su carácter complejo (Morin, 1994). La identidad tiende a identificar a los iguales dentro de un mismo grupo, e incluso a una persona, en relación con otros grupos o personas, dando sentido propio y posibilitando la afirmación y autoafirmación. De este modo, podemos decir que la identidad une, como queda reflejado en aspectos tales como ser mujer, orgullo gay, etcétera.

Al mismo tiempo, la identidad sirve también para diferenciar a unos y unas de otros y otras. Marca distancia entre los no iguales y abre un espacio entre los que se ubican en un lugar y los que no lo están. En este sentido, la identidad marca distancias y diferencias entre los iguales y los no iguales. En algunos casos, muchos por desgracia, esa diferenciación es una clara negación del otro, lo que acarrea problemas nada baladíes.

\footnotetext{
24 Es necesario recordar que no existe un único feminismo, siendo obligado hablar de este en plural: feminismos. De hecho, en nuestro caso, tomaremos aportaciones de más de uno, aunque alguno tendrá más peso que otros.
} 
Así, la identidad se mueve en un terreno complejo, que, a la vez, une y diferencia. ${ }^{25}$ Seguramente sea en este factor en donde resida tanto su limitación como su fuerza. Una dualidad que se ha desarrollado, la más de las veces, de la siguiente manera: a mayor identificación y afirmación interna, mayor es la diferenciación y no reconocimiento del otro. Cuanto más se tira de un hilo, más lejos queda el contrario. A mayor diferenciación y afirmación propia (del adentro), mayor desconsideración del otro (del afuera).

Como nos ha recordado Jeffrey Weeks, si miramos la historia de los grupos de afirmación sexual, apreciamos como estos han ido feneciendo en función de cómo han actuado ante dicha situación. Si se tira excesivamente de un lado, la negación del otro suele conllevar cierto tipo de guetificación que supone su práctica desaparición. Por el contrario, cuando se diluye en exceso su personalidad, suele producirse su desaparición por el camino inverso, es decir, por ser asimilados. Ambas realidades y tensiones forman parte, aunque no solo, de los distintos grupos que llevan a cabo exigencias sobre politicas de identidad (Weeks, 1993, pp. 293-334).

Por otro lado, es una constante que se establezca algún tipo de relación entre las identidades individuales y colectivas. La vinculación entre estas identidades es, de hecho, variada y múltiple, habiéndolas más fuertes y más débiles, aunque siempre se dé algún tipo de relación entre ellas.

Las experiencias organizativas sociales y políticas más significativas dentro de la problemática de género y sexo, es decir, las que mayor fuerza social e impacto ambiental tienen y han tenido, se han caracterizado, en la mayoría de los casos, por establecer un tipo de relación entre las identidades individuales y colectivas ${ }^{26}$ determinada por tres rasgos.

\footnotetext{
25 Una mirada retórica, y crítica, sobre la 'lógica de la identidad' en Carrillo y Saibacam (2010, pp. 97-102).

26 Para un recorrido feminista crítico por esta y otras problemáticas, ver Uría (2009).
} 
En primer lugar, por el cuestionamiento de la relación existente entre lo público y lo privado en nuestras sociedades. Este elemento es uno de los ejes característicos de la fuerza de todos estos grupos y movimientos. La famosa consideración de que lo personal es político está por detrás de estos planteamientos, sobre todo a partir de los años sesenta. ${ }^{27}$ No obstante, hay muchas formas de abordar la idea de $l o$ personal es político. De manera general, supone un cuestionamiento de la dicotomía clásica público versus privado, aunque este es plural. Hay quienes cuestionan esta dicotomía con la intención de negar la diferenciación entre lo público y lo privado (que tendría como consecuencia una relación determinista entre lo individual y lo colectivo). Pero también hay quienes pretenden hacer una redefinición, más o menos profunda, de esta sin establecer ninguna relación determinista entre lo individual y lo colectivo. ${ }^{28}$

En segundo lugar, por la necesidad de dar reconocimiento social y político a una opresión o injusticia, la cual requiere de una entrada en la arena pública que sea nítida y contundente. Una forma habitual de reafirmar este hecho es reforzar y simplificar (por múltiples vías) la identidad colectiva del grupo correspondiente, lo que genera mayor seguridad y firmeza a los planteamientos propios, afirmando una identidad de la que hay que sentirse orgulloso y orgullosa, dignificando así una parte de las vidas de ciertas personas que han sido negadas (Weeks, 1993, pp. 293 y ss.).

Y, en tercer lugar, por el hecho de proyectar una identidad individual - una forma particular de entender, como sentirse gay, lesbiana, transexual, etc. - como la representante genuina de la identidad colectiva. Una proyección que viene cargada por dos rasgos muy significativos. Por un lado, supone cosificar la identidad individual, definiendo una identidad de género y de sexo como la verdadera identidad (esencialismo); y, por otro, conlleva que esta identidad individual

\footnotetext{
27 Ver Uría (2009).

28 Este sería el caso de la retórica bumanista que no remite a un ágora totalizante, sino a la existencia de espacios públicos internos como realidades fundantes de lo público; una idea de lo público sustentada en la libertad. Ver Fdez-Llebrez (2009, p. 415).
} 
actúe como modelo para el conjunto del grupo, transmutándose la parte hacia el todo y uniformizándose, también, la propia identidad colectiva. El traspase de una identidad individual a otra colectiva se suele justificar, precisamente, porque se piensa que la identidad solo une a los iguales y no a los diferentes, estampándose las identidades colectivas sobre las individuales como si fueran sellos sobre papel en blanco, quedando calificadas las denominadas anomalias como opciones meramente personales, desgajándolas así de todo su carácter social.

Que las identidades de género y de sexo son realidades complejas es una constante teórica e histórica que forma parte de los estudios y las prácticas sobre las identidades desde hace ya mucho tiempo, por lo menos dentro del mundo moderno. Lo mismo ocurre con el hecho de que algún tipo de relación hay entre las identidades individuales y las colectivas, ${ }^{29}$ mostrándose así su historicidad, contingencia y apertura a la hora de entenderlas y estudiarlas. Es este carácter abierto el que nos muestra la posibilidad de replantear el marco teórico disponible. Un replanteamiento que tiene consecuencias, no solo sobre la relación entre identidades, sino también sobre la forma de definir la propia identidad, afectándole cuanto menos en dos aspectos: en su carácter natural o construido y en la vinculación entre diferencia e igualdad a la hora de su conceptualización.

En definitiva, lo que no ha sido estudiado hasta el momento en la teoría política es la crucial cuestión de cómo democratizar las identidades entendiendo que son lugares donde pueden habitar diferencias. De ahí que sea preciso abrir este campo de reflexión. Para ello comenzaremos por conocer cuál ha sido la forma habitual de definir las identidades en el terreno del género y el sexo para comprobar sus posibles limitaciones.

\footnotetext{
29 Para esta relación, es de interés el concepto de articulación desarrollado por Chantal Mouffe. Ver Mouffe (2003, pp. 95 y ss.). Para una aproximación a las identidades colectivas y su relación crítica con el enfoque de Mouffe, ver Engelken-Jorge (2010, pp. 80 y ss.).
} 


\section{La falsa inconmensurabilidad entre los sexos}

Es sabido que el género es algo cultural que ha ido cambiando a lo largo del tiempo y del espacio. Tal consideración está hoy comúnmente aceptada. Pero resulta que algo parecido ocurre si hablamos del sexo, porque la sexualidad, así como la identidad sexual, son cuestiones que también han cambiado a lo largo de la historia. ${ }^{30}$ Esta cuestión ya no está tan asumida, siendo uno de los debates de mayor resonancia dentro de la teoría feminista contemporánea.

Si miramos la historia, nos encontramos con dos teorías a la hora de definir el sexo. Por un lado, está la teoría clásica sobre el sexo que, sin dejar de ser usada años más tarde, llega como teoría dominante de carácter explicativo hasta el siglo XVII y principios del XVIII. Esta teoría, defendida, por ejemplo, por Galeno, es conocida como la de sexo único e interpreta a los "cuerpos masculinos y femeninos de forma jerárquica, verticalmente, pero como versiones ordenadas dentro de un solo sexo" (Laqueur, 1994, p. 31).

Por otro lado, está la teoría moderna de los dos sexos inconmensurables que vino a sustituir a esta y que se desarrolla a lo largo del siglo XVIII, que tiene su apogeo en el XIX y llega hasta nuestros días. De ahí que tenga razón Thomas Laqueur cuando afirma que "el sexo tal y como lo conocemos [hoy] fue inventado en el siglo XVIII" (Laqueur, 1994). Entonces fue cuando los órganos de reproducción pasaron a ser lugares paradigmáticos que manifestaban la jerarquía, actuando como el fundamento de la diferencia inconmensurable (Laqueur, 1994, pp. 258 y 259). Así, estructuras que se habían considerado comunes a los hombres y las mujeres, como el esqueleto y el sistema nervioso, fueron diferenciados para que se correspondieran con el verdadero hombre y la verdadera mujer. El cuerpo, en particular el de la mujer, se

\footnotetext{
30 La obra clásica a la que se remite cuando se habla de esta cuestión es a la Historia de la sexualidad de Foucault (1992). Pero no es necesario seguir los postulados foucaultianos para aceptar el carácter constructivo de la sexualidad. Para un ejemplo de ello, ver Nussbaum (2005, pp. 235-274). Para un recorrido por la historia de la sexualidad, y en concreto de la homosexual, en el mundo griego: Dover (1986); y, para una mirada que llega hasta el siglo pasado: Laqueur (1994).
} 
convirtió en la regla de oro del discurso social, con todo lo que a él iba vinculado.

Rasgos supuestamente naturales, como el pretendido desapasionamiento de las mujeres, la carga de la naturaleza y de los procesos cíclicos, los órganos reproductores (que incluso se cambiaron: la matriz, antes vista como una especie de falo negativo, pasó a ser el útero), se convirtieron en la seña de identidad, nunca mejor dicho, de toda una nueva teoría sobre el sexo y el género. De esta manera, se puede decir que las ideas de las "mujeres como poco afectadas por la sensualidad, como una especie de ángeles, como una 'raza' más pura... destinada a inspirar en el resto de la condición humana sentimientos nobles, generosos y de fidelidad" (Laqueur, 1994, p. 332), ${ }^{31}$ fueron una creación cultural de los hombres y las mujeres de las clases medias de la época; no quedándose solo en su época, sino extendiéndose hasta la actualidad.

Esta concepción del sexo requiere una nueva epistemología para la cual las categorías hombre y mujer son sustancias naturales diferentes que definen "dos sexos biológicos opuestos e inconmensurables" (Laqueur, 1994, p. 226) y que se reconocen dentro de un marco binario, dicotómico y en contradicción. Epistemología esta que no solo se deja ver en el ámbito privado, sino que se traslada al ámbito público a través del concepto de contrato social de origen roussoniano. ${ }^{32}$

Así, la idea de que hay dos sexos inconmensurables era, y es, un producto cultural en la misma medida que lo era, y lo es, la de que hay un 'sexo único' (Laqueur, 1994, p. 264). En palabras de Laqueur: “Casi todas las afirmaciones relativas al sexo están cargadas desde el principio por la repercusión cultural de las mismas propuestas" (1994, p. 37). Por ello, es oportuno decir que la identidad no solo es algo construido, sino que las referidas al género y al sexo también lo son (Nussbaum,

\footnotetext{
31 Para esta cuestión, ver también: Davidoff y Hall (1994).

32 Ya es clásica la crítica de Mary Wollstonecraft al planteamiento de Jean-Jaques Rousseau (Wollstonecraft, 1994, pp. 215 y ss.). Para una crítica reciente al contractualismo desde un punto de vista humanista y feminista: Nussbaum (2006).
} 
2005, pp. 240-274). Reconocer esta contingencia no significa negar que las diferencias y las semejanzas, más o menos recónditas, estén por todas partes, pero sí que cuáles de ellas se tienen en cuenta, y con qué objetivo, es algo que se define fuera de la estricta investigación empírica. ${ }^{33}$

Precisamente por esto, es pertinente pensar las identidades sexuales y de género de forma distinta a como se hace hoy en día. Incluso, es necesario ver si no hay ya otras formas de aproximación a la identidad de género y de sexo que pongan en entredicho todo este entramado teórico, abriéndonos otras posibilidades para el pensamiento y la vida democrática.

\section{5. ¿Del sexo al género o del género al sexo?}

Para seguir ahondando en esta cuestión, es fundamental analizar la singular concepción de la identidad sexual y de género que la teoría de los dos sexos inconmensurables, de origen dialéctico romántico, suscita y promueve. ${ }^{34}$

La manera tradicional de hacer dicha incursión es recurriendo al vocablo patriarcado, pero consideramos que tal denominación, así como parte de su definición, no recoge bien la complejidad del asunto que se debe tratar. Otras veces, la forma de denominación ha sido la expresión "sistema sexo/género" que puso Gayle Rubin en circulación a mediados de los setenta, la cual ha sido reformulada años más tarde — precisamente, entre otras autoras feministas, por la propia Rubin (1989)-. No obstante, no es este el momento de entrar

\footnotetext{
33 Que hay hombres y mujeres es algo incuestionable. Esto ha sido así a lo largo de la historia humana conocida. Y lo ha sido así también tanto en la época donde predominaba la teoría de un único sexo, como en la de los dos sexos. Por lo tanto, eso no es lo que está en discusión, sino las justificaciones y explicaciones teóricas que definen dichas categorías. 34 Para un recorrido por la teoría dialéctica y su relación con las concepciones predominantes sobre el género: Fdez-Llebrez (2008, pp. 85-102). Que esta identidad nazca en el mundo moderno no significa que sea representativa de toda la modernidad. En este sentido, como en tantos otros, es preciso hablar de modernidades, en plural.
} 
en estas disquisiciones y no porque no tengan interés. En nuestro caso, usaremos, indistintamente, las expresiones orden normativizado sexual y de género, sistema de sexo/género o la de ordenamiento sexista, aun reconociendo que dichas expresiones tienen sus problemas analíticos, pero lo intentaremos resolver no tanto en el terreno nominal (qué expresión o palabra usar), sino en el conceptual (a qué nos referimos en concreto). En este sentido, los rasgos que podemos destacar son los siguientes.

El primero se refiere a la idea según la cual la definición del sexo actúa como realidad verdadera ya existente sobre la que se construyen los géneros. La identidad sexual es algo natural que da consistencia objetiva y científica a la teoría de los dos sexos, de tal modo que son la biología y la medicina las que actúan como campos de reflexión a la hora de definir al sexo y de señalar cuántos hay. Esta concepción supone una fundamentación naturalizada de la creencia de que hay dos sexos, y solo dos, no existiendo otras posibilidades.

El segundo rasgo remite a que dicha definición del sexo es, además, de carácter dicotómico. A un lado está lo masculino (la identidad masculina, el hombre) y al otro lo femenino (la identidad femenina, la mujer) configurando dos polos diferenciados entre sí y quedando en medio una sima enorme que los separa. Este binarismo se caracteriza por su dimensión dicotómica de tal modo que, si no se es una cosa (no se es hombre), inexorablemente se es la otra (ser mujer). Esta concepción se desarrolla creando categorías estándar que actúan a modo de estereotipos (Mosse, 2000, p. 9) contradictorios que califican y clasifican a la identidad masculina y a la femenina.

El tercer rasgo implica que tal estereotipación no supone que no se den relaciones entre ambas categorías (sexo y género), ni entre ambos grupos (los hombres y las mujeres). La relación que se da entre hombres y mujeres es asimétrica, lo que se reflejada en la desigual relación de poder que hay, y sigue habiendo, entre ambos. Pero también es de complementariedad, percibiéndose ambas identidades como si una completara a la otra. Algo que se manifiesta en la cuestión sexual (la heterosexualidad obligatoria o generalizada dentro de la tradicional idea 
de la media naranja), pero también en ciertos rasgos culturales (ternura/ firmeza, débil/fuerte, etc.).

Por su parte, la relación que hay entre lo sexual y lo genérico es una muy específica y de carácter mecanicista. Una vez identificado qué es lo sexual (que es natural) se le proyectan, de manera automática, los atributos a los géneros correspondientes (heterosexuales, viril, reproductor,...). El resultado de esta forma de relación es que hay dos géneros (cultural), precisamente, porque anteriormente ha habido dos sexos (natural), configurándose la pirámide sexual de la que, tan lúcidamente, nos habló Rubin (1989, pp. 140 y ss.). ${ }^{35}$

Como cuarto rasgo destaca que tanto la identidad sexual como la de género son cuestiones trascendentales para las personas, cobrando una importancia muy relevante en nuestras vidas. Relevancia que hará que la sexualidad adquiera una dimensión pública, definiéndose desde un punto de vista moral y convirtiéndose en objeto de control. Es así como aparecerá lo que se denomina la buena y la mala sexualidad, que conllevará un proceso de normativización y reglamentación respecto al sexo y el género muy importante. Entre otros autores, esto ha sido estudiado por Michel Foucault para la Inglaterra victoriana y por George Mosse para el caso alemán (Foucault, 1992; Mosse, 2000). Ambos autores muestran como algo que no tenía relevancia pública termina formando parte de los elementos que definen nuestra vida en común y lo hace, además, de una manera destacada.

Como quinto rasgo destaca la forma que tiene este razonamiento binario de definir a los seres humanos en general (Mosse, 2000, pp. 23-49). Tal y como plantea Benhabib, esta concepción solo puede ser abordada satisfactoriamente haciendo de la definición de lo masculino algo con un doble significado: remitiendo, al mismo tiempo, a lo específico (los varones) y a lo general (hombre como ser humano). Un doble significado que tendrá como consecuencia que lo general se identifique

\footnotetext{
35 No obstante, también pudiera ser al contrario, tal y como plantea Christine Delphy, de tal modo que lo primero haya sido el género y 'luego’ el sexo. Para una mayor profundización en esta polémica, ver Delphy (1993).
} 
con lo masculino y viceversa (Benhabib, 1990, pp. 135 y ss.). No obstante, hay veces que la consideración de la identidad sexual como algo trascendental(ísima) toma otro camino, aquel que postula una diferenciación radical entre géneros y sexos, siendo imposible imaginar ni hablar de ningún tipo de bumanización general. ${ }^{36}$

Pero sea por una imposible generalización o porque se establezca una sinécdoque (en la que la parte masculina sustituye al todo), la cuestión es que, para esta concepción, la identidad es una y solo una: la identidad es idéntica. De esta forma, si hay (una) identidad, no hay diferencia (interna) posible y, si hay diferencia (interna), no hay identidad posible. La identidad es vista — no oída — como un juego de contradicciones. De ahí que quien cruce las fronteras establecidas sea visto como un ser o bien sin identidad y, por lo tanto, perdido y en constante crisis, o bien un ser directamente trastornado. Pero, sea como fuere, lo normal no pasa por dicho cruce, sino por el camino contrario.

Pues bien, si queremos decir, y saber, algo más sobre ese supuesto cruce imposible, es pertinente abordar lo que dicen y hacen los y las transexuales en relación con la identidad sexual y de género, ya que ellos y ellas son un ejemplo real de dicho cruce.

\section{Transgenerismos e identidades de género y sexual}

Como es bien sabido, y desde un punto de vista general, una persona transexual es aquella en la que su identidad de género y sexual psíquica no se corresponde con su identidad morfológica (física). Es decir que, teniendo un cuerpo de hombre o de mujer, ella o él se siente lo contrario a su aspecto físico.

Hasta hace muy poco tiempo esta situación fue considerada como un trastorno psiquico, llevando aparejadas toda una serie de tratamientos médicos de carácter psiquiátrico nada despreciables y muy dañinos para tales personas (Nieto, 1998, pp. 11-37). Eran tratados y tratadas,

36 Un ejemplo de este planteamiento lo tenemos en Irigaray (2009). 
y todavía hoy en cierta medida y en ciertos lugares lo son, como una 'especie de alienígenas': como seres amorfos y depravados. Hoy, y gracias a las reivindicaciones de grupos de transexuales y de algunos grupos feministas, ${ }^{37}$ esta concepción está cambiando a mejor, aunque todavía no lo suficiente.

Lo que sí es un elemento común, por lo menos dentro de la mayoría de especialistas, así como en el conjunto de los propios grupos de transexuales, es la aceptación de que, en este conflicto de identidades, es el elemento subjetivo el que más pesa. Es decir que no se trata de ningún trastorno psíquico de carácter clínico y que, en todo caso, debe ser el cuerpo, la morfología, la que se adapte a dicha realidad, para lo cual es necesario que haya recursos financieros de carácter público que atiendan tal demanda.

Esta consideración ya supone abrir una vía de quiebra para con el modelo binarista, puesto que la identidad puede desgajarse de la morfología, de tal modo que es la subjetividad la que la termina definiendo, lo que deja maltrecha la idea naturalizada y corpórea que identifica a la identidad sexual, a qué es un sexo, con su apariencia externa. Toda una ruptura que conlleva un primer paso en el proceso de distanciamiento respecto de la concepción identitaria binaria (Nieto, 2008; Soley-Beltrán, 2009).

No obstante, dentro de los y las transexuales se pueden apreciar dos maneras de abordar esta denominada crisis de identidad. Los hay, y las hay, que no soportan vivir dentro de un cuerpo que no se corresponde con su identidad subjetiva y desean operarse con el propósito de adecuar su morfología a su subjetividad. Pero también los hay y las hay que, si bien reconocen esa disparidad entre la morfología y la subjetividad, se sienten bien con dicha dislocación, llegando a convivir con un cuerpo que, morfológicamente, es mitad masculino, mitad femenino (v. g., órgano genital masculino y pechos), desestructurando, así, la distinción bipolar entre hombre y mujer.

37 Para este menester, ver Garaizabal (1998, pp. 39-62). 
Desde nuestro punto de vista, tanto quienes se quieren operar como los que no forman parte del colectivo de transexuales, aunque, a veces, a unos y unas (a quienes sí quieren operarse) se les denomina como transexuales y a los otros u otras (a quienes no desean operarse) se les denomina como transgenéricos. Si bien tanto una como otra experiencia conforman la realidad transexual, en este artículo nos vamos a centrar en aquellos y aquellas que, por motivos variados, se sienten cómodos en esta hibridación morfológica y psíquica en la que viven y que, siendo diferentes a los drag queen o los travestis, tienen una cercanía con estos a la hora de abordar la caracterización de la identidad masculina y femenina. Y, para que no haya confusión en el lenguaje, y aunque nos parece más adecuada la expresión de transexuales (en plural), tomaremos la expresión transgenéricos para denominar ese colectivo específico.

De manera resumida, podríamos decir que los y las transgenéricas construyen una identidad de género que cuanto más diferente es en el sexo (cuando mezclan en un solo cuerpo, por ejemplo, órganos genitales de un sexo con morfologías del otro sexo) menos distinción y desconsideración hay para con el otro género, al asumir, en una misma corporalidad, rasgos culturales masculinos y femeninos. Al mezclar sus diferentes morfologías sexuales, también hibridan en cuanto a los géneros, siendo algo que afecta, además, tanto a su presente como a su pasado y a su futuro.

Por lo tanto, a mayor diferenciación sexual, es decir, a mayor distancia en relación con los dos sexos conocidos tradicionalmente, no hay más desconsideración hacia el otro (género y sexo), sino, por el contrario, mayor aproximación hacia el otro (género y sexo).

Si analizamos atentamente lo dicho, comprobamos cómo esta redefinición supone un claro cuestionamiento de aquello que caracterizaba a la identidad dicotómica típica de las políticas de la identidad culturalistas. Para esta concepción, lo que define a la identidad es que esta une y al hacerlo marca distancias con lo diferente, de tal modo que, a mayor diferenciación y afirmación propia, mayor distinción respecto del otro. De ahí que dichas politicas de identidad marquen muy claramente 
las diferencias entre los distintos grupos (mujer, lesbiana, gay,...), pues entienden a cada uno de estos como contradictorios entre sí.

Sin embargo, en el caso de los y las transgenéricas la cosa no es así. Es verdad que su identidad marca distancias en cuanto al cuerpo (morfológico), pero no lo es que tal diferenciación conlleve una mayor distinción respecto del otro (ya sea hombre o mujer), sino más bien al contrario: una menor distinción que nos expresa una relación de continuidad entre ambos sexos. Esta concepción de la identidad es minoritaria y particular tanto en cuanto caracteriza una forma de entender la transexualidad. Pero también puede tener una dimensión más amplia al repercutir sobre la definición general de la identidad sexual y de género imperante hoy en día. ${ }^{38}$

Entre las características definitorias del denominado sistema sexo/género, destaca su concepción dicotómica y dogmática a la hora de apelar a los géneros y los sexos. Es cierto que, si tomamos la expresión más dura o conservadora de este planteamiento, su rigidez es tal que no cabe ni la posibilidad de aceptar la diversidad de géneros, de sexos y de opciones sexuales. Pero, si nos aproximamos a versiones menos estrictas o más progresistas, nos encontramos con que no es incompatible la aceptación de esta mirada binarista con el reconocimiento e igual consideración de, por ejemplo, diferentes opciones sexuales.

Es decir, se puede asumir esta aproximación teórica y, a la vez, reconocer la legitimidad de cuantas opciones sexuales se quiera (lesbianismo, heterosexualidad, etc.). Es más, desde este planteamiento binarista, también es factible reconocer a la transexualidad que tiene como fin la operación, más allá de si se está de acuerdo o no con financiar públicamente dichas operaciones. Esto es así porque, al realizarse dicha operación, ${ }^{39}$ lo que se está produciendo es una readecuación, en términos de identidad, a uno de los dos sexos establecidos, lo cual

\footnotetext{
38 Para la relación entre las identidades mayoritarias y minoritarias, ver Sedgwick (1998, pp. 11-90).

39 Acto legítimo que, desde nuestro punto de vista, debe estar financiado públicamente.
} 
no vulnera en absoluto la dicotomía existente, sino que más bien la reafirma. ${ }^{40}$

Sin embargo, lo que resulta complicado aceptar para el planteamiento binarista es una realidad que cuestione sustantivamente su background en relación con la identidad de género y de sexo. Y eso es lo que precisamente ocurre cuando pensamos en el transgenerismo, es decir, en la transexualidad que no tiene como meta la operación. Y ¿por qué? El background que define al conjunto de la teoría binarista, en cuanto a su definición del sexo, se caracteriza por desplegar una concepción dicotómica según la cual hay dos, y nada más que dos, sexos de carácter opositivos y en contradicción en los que tienen que encajar y entrar todas las identidades sexuales existentes. Un planteamiento similar ocurre a la hora de hablar del género, cuando se señala que hay dos y solo dos géneros y que estos también son de carácter opuesto.

Es así como dicha concepción tiene capacidad para aceptar una variedad de opciones sexuales, lo cual no contradice sus supuestos teóricos, pero, del mismo modo, difícilmente se acepta una realidad que vaya más allá de tal dicotomía opositiva (sea esta heterosexual versus homosexual, femenino versus masculino, u otras), tal y como ocurre con las y los transgenéricos. De ahí que este planteamiento les termine dejando fuera al no encajar en dicha dualización. Una exclusión que hace que los y las trangenéricas acaben siendo o bien la más pura nada (representando la quintaesencia de la inexistencia humana), o bien formen parte de algún programa clínico sobre trastornos de personalidad.

Lo que los y las transgenéricas plantean es una hibridación (Benhabib, 2006b, p. 61 ${ }^{41}$ que mezcla partes de la masculinidad y partes de la feminidad, produciendo una dislocación identitaria que supone un cuestionamiento de la masculinidad y la feminidad como dos todos ya

40 Esto no quiere decir que todos los y las transexuales que se operen acepten dicha lógica binaria, sino solo que tal proceso se puede desarrollar coherentemente dentro de tal planteamiento, lo que no es lo mismo.

41 También puede acudirse a Haraway (1995). 
prefijados. Este cruce sexual y de géneros de los y las transgenéricas significa una redefinición de la relación entre los géneros y los sexos al establecer un continum entre ambos, lo que rompe con la concepción binaria establecida. Un continum que no conlleva desconsiderar ni al hombre ni a la mujer, sino, por el contrario, un proceso de hibridación en cuanto a los géneros y sexos. Una hibridación radical que, parafraseando a Benhabib, supone entender las identidades de género y sexual como realidades polivocales, descentradas y fracturadas (2006b, p. 61); una hibridación que les ubica fuera de la escala social establecida al considerarse dicho mestizaje como una impostura moral y social (Rubin, 1989, pp. 159 y ss.). Tan es así que, desde el punto de vista sexual, son considerados y consideradas sin sexo oficial.

Transgredir los géneros supone cuestionar los roles establecidos, lo cual no encaja bien con el binarismo de género. Pero dicha desubicación no tendría que ser vista así por los propios grupos de afirmación sexual ni por los de identidad de género. En ningún caso, el o la transgenérica, en lo referido al género, supone algo muy diferente de lo que gais, lesbianas, mujeres del movimiento feminista y personas vinculadas a esta tradición puedan plantear. Sí es más visible, más personal, más llamativo y más extremo, si se quiere, pero no tiene por qué ser algo ajeno a tal realidad.

Sin embargo, su hibridismo sexual sí que desplaza a los y las transgenéricas fuera de los límites en los que se mueven tanto el binarismo social imperante como la mayor parte de los propios grupos de afirmación sexual. Para el planteamiento binario, y para ciertos grupos de afirmación, se será gay, lesbiana, heterosexual u otra cuestión, pero se es, a la vez, o mujer u hombre y con una clara morfología. De ahí que el transgenerismo, al romper dicho planteamiento dicotómico, no solo cuestiona el background socialmente existente, sino también el que sostiene a ciertos grupos de afirmación sexual.

Es cierto que la hibridez morfológica y subjetiva de los y las transgenéricas les diferencia de manera profunda. Pero, también, que es una diferenciación que no crea una barrera más. Más bien es al contrario: su diferencia sexual lo que hace es aproximar géneros y sexos. Y al 
hacer esto nos señalan la pertinencia de diferenciar tres dimensiones que, para la teoría de los dos sexos inconmensurables y su identidad binaria, se consideraban unidas: el sexo anatómico, por un lado; la identidad de género (cómo uno o una se siente), por otro; y, por último, la actuación del género (los rasgos atribuidos a cada género) (Butler, 1999, p. 174). La ruptura de la unidad entre el sexo y el género implica reconocer un dinamismo identitario a la hora de definir los géneros y los sexos, que, debido a su capacidad de desplazamiento, pone en solfa la propia concepción binarista. Un dinamismo que da sentido a lo que, siguiendo a Benhabib, podríamos denominar como "construcciones dinámicas de la identidad” (2006b, p. 117) y que va a tener repercusión no solo sobre los y las transgéneros, sino también sobre la concepción binaria que caracteriza a las identidades masculinas y femeninas imperantes hoy en día. ¿Y en qué sentido es así?

En primer lugar, ya no apelaríamos a una supuesta verdadera identidad de género y sexual de carácter esencialista y binarista. Más bien, hablaríamos de una identidad construida social y personalmente que, por ser tal, es reversible y, por ende, no necesariamente dicotómica. Un constructivismo fundacional que no defiende que seamos una página en blanco, sino una interacción entre lo biológico, lo social y lo psicológico, donde la última palabra todavía no está escrita, teniendo capacidad para actuar sobre dicha compleja realidad (Fdez-Llebrez, 2004, p. 19; Weeks, 2001, pp. 151 y ss.).

En segundo lugar, tampoco hablaríamos de los hombres y de las mujeres como dos esencias, como dos sustancias, radicalmente distintas que contienen dos universos ya predefinidos. Por el contrario, hablaríamos de los hombres y las mujeres como categorías sociales opolíticas, interconectados entre sí, a través de un continumm entre dos polos que posibilita la transferibilidad, compleja y múltiple, de los diferentes atributos de género y sexo, haciendo de la identidad una realidad diversa y mutable (Weeks, 2001, p. 179). ${ }^{42}$ Una transferibilidad en donde la hibridación de sexos y géneros es una posibilidad más. Pero, ahora, es una posibi-

42 Para la relación entre identidades cambiantes y la ciudadanía democrática, ver Wolin (2008b, pp. 402 y ss.). 
lidad real integrada dentro de los marcos de género y sexuales y no una especie de anomalía, como ocurre en la concepción binarista. Unas identidades sexuales y de género que al estar insertadas en dicho continuum, y no en su dicotomía, pueden despedazar el binarismo sexual y de género imperante, afectando, así, tanto a la identidad masculina como a la femenina.

Esto no significa que no haya diferencias sociales y políticas, que - como las semejanzas - las hay. ${ }^{43}$ Estas diferencias quedan relacionadas con la desigual relación de poder existente; con los procesos de socialización y la plural interiorización de las experiencias (personales y culturales); con la estereotipación, trascendentalidad y fijación de las identidades ya establecidas; y con aspectos biológicos y morfológicos. Pero no ya con una supuesta ontología de género ni sexual que remita a dos entes distintos (ya sea apelando a razones biológicas o culturales).

Por todo esto es por lo que hombres y mujeres no transgenéricas (drag queen, travestis, hombres y mujeres en general) pueden identificarse y desarrollar dicha transgresión genérica. Y lo pueden hacer sin tener que dejar de sentir lo que uno o una quiera sentir, sino redefiniendo el concepto de identidad de género y de sexo imperante. No obstante, esto no es ni sencillo ni baladí, siendo preciso reconocer las dificultades que ello comporta, ya que no hablamos de personas como páginas en blanco. Pero que este proceso sea complicado no significa que sea imposible, ni que no tengamos la capacidad para sentirnos libremente.

Lo que sí supone es un reto para que hombres y mujeres podamos construir identidades de género y sexuales no dicotómicas ni estereotipadas, siendo conscientes de que la diferenciación no es sinónimo de negación, sino que puede llevar parejo una reconsideración transversal de los propios géneros y sexos. Como dice Benhabib, hablamos de una

\footnotetext{
43 Diferencias de género que, al cruzarse con otras variables, como la raza, etnia, clase social, etcétera, dibujan un panorama profundamente plural que es preciso atender. Para esta cuestión, ver Fraser (2008, pp. 31 y ss.).
} 
reconsideración que sea capaz de "captar las transiciones fluidas que pueden producirse en el estatus de los grupos, a medida que estos se desplazan de una categoría a otra" (Benhabib, 2006b, p. 117). Una forma de definir las identidades de género y de sexo como posibilidades modificables que no remiten a una esencia inamovible y que rompe con las políticas de enclave cultural al permitir que "el disenso, el debate, la controversia y el cuestionamiento ocupen el centro" (Benhabib, 2006b, p. 129) de sus prácticas.

\section{Género y democratización de las identidades}

Reconocer que las identidades de género se caracterizan por su fluidez supone replantearnos no solo nuestra privacidad, sino también nuestros espacios públicos (Benhabib, 2006a, pp. 17 y ss.). Conlleva relacionar la democratización pública con la privada, puesto que la democratización de nuestras identidades colectivas, relativas al género y al sexo, requiere desafiar la lógica oculta de muchas de estas categorías. De ahí que hayamos dicho que las identidades de género y sexual sean categorías políticas. No porque contengan un cariz ideológico - que no lo tienen—, sino porque su sentido lo adquieren por su incardinación en la vida pública y, en concreto, en una vida pública democrática.

En este sentido se ha expresado Benhabib cuando manifiesta que el objetivo de esta concepción teórica "sería llevar a la sociedad democrática hacia un modelo de vida pública en la que los relatos de autoidentificación serían más determinantes del propio estatus en la vida pública que los indicadores y los índices que otros nos imponen" (2006b, p. 143). Incorporar esta concepción identitaria sobre los géneros y los sexos al pensamiento y la práctica democrática supone abrir una perspectiva de inclusión para los y las transgenéricas, pero también para aquellas mujeres y hombres que no se sientan reconocidos, ni reconocidas, dentro de los estereotipos dicotómicos masculinos y femeninos imperantes hoy en día. Un planteamiento que nos permite reconocer más posibilidades para desplegar una manera de vivir más igualitaria, libre y digna. Objetivos estos que forman, o deben formar, parte del legado básico de cualquier teoría democrática de carácter moderno. 
En la identidad binaria y dicotómica solo caben quienes se ubiquen en cada uno de los dos polos establecidos, abriéndose una sima tremenda para quienes quedan en el medio. Una mirada que solo permite el desarrollo de identidades dogmáticas y rígidas en las que se da una relación de (mono)causalidad entre sexo y género. Estas identidades dicotómicas se ven como las verdaderamente legítimas y son las que tendrán, y tienen, consideración y reconocimiento tanto público como privado. Es una concepción cerrada de la identidad que termina produciendo una menor pluralidad.

Sin embargo, en la perspectiva de la identidad como continuum caben tanto los polos como los puntos intermedios que delinean su interconexión, lo que genera una profunda y compleja desestructuración de la (establecida) relación entre sexo y género. De este modo, la sima existente se llena cubriéndose de posibilidades, pudiéndose dar identidades tanto claras como ambiguas al desarrollar un planteamiento en el que la fluidez siempre está presente. Su capacidad de reconocimiento es mayor, por lo que se ensancha nuestra pluralidad. Es decir, es una concepción abierta de la identidad que termina agrandando la democracia, precisamente, porque permite incorporar nuevos campos de posibilidades para nuestra vida.

Pero esta ruptura con el binarismo establecido también supone un reconocimiento de la 'autodesignación identitaria' frente a la 'heterodesignación normalizadora' (Garaizabal, 1998, pp. 59 y ss.), lo que facilita un planteamiento crítico contra la normativización sexual y de género. Un pensamiento crítico que nos hace más libres y nos permite un mejor y mayor gobierno del ciudadano democrático. ${ }^{44}$

No obstante, esto no significa que se hayan resuelto las cuestiones de la identidad de una vez para siempre. La riqueza de la identidad como continuum está, precisamente, en la posibilidad de mantener vivas las contradicciones mostrando su carácter fluido, dinámico e híbrido.

\footnotetext{
44 Para el gobierno del ciudadano, ver Roiz (2003, pp. 321 y ss.; 2008, pp. 85 y ss.) y Alonso (2010, pp. 218 y ss.). Para la 'democratización del self', puede acudirse a Wolin (2008b, pp. 400-401).
} 
De ahí que no sea adecuado entenderla como la nueva y definitiva solución ante los problemas de la identidad en nuestras democracias. Es más, para que los propósitos democráticos sean más fructíferos, muchas veces el continuum identitario requerirá un diálogo complejo (Benhabib, 2006b, p. 129) con ciertas politicas de identidad ${ }^{45}$ y sus respectivos derechos afirmativos. Un proceso de diálogo que, siguiendo a Benhabib, puede denominarse como de "reconstrucción reflexiva de las identidades" (2006b, p. 129) y que brinda una alternativa más democrática que la política binarista imperante. Una definición de la identidad que, aceptando su dimensión contingente, pretende desplegar una mirada lo más inclusiva, libre y sana posible de nuestras vidas.

En definitiva, una forma de acercarnos a la identidad en la que hay un mundo interno en el ciudadano de tal modo que su reconocimiento y capacidad de enjuiciamiento sobre este nos permite hablar de una necesaria democratización de las identidades como una tarea cívica por la que hay que trabajar. Una democratización que entiende la fluidez en la que nos constituimos, así como nuestras pluralidades y la labor de artesanía diaria que todo ello conlleva: y esto con las herramientas reales — nuestras razones, anhelos, sueños, inquietudes,...- de las que disponemos los ciudadanos de carne y hueso; y no con las querencias de las ideologías románticas en donde la pulsión y la totalización sustituyen la profundidad, complejidad y matización de la vida cívica.

Pero, más allá de esta mirada teórica, sería de interés ver cómo esto forma parte de nuestras vidas y ha dado frutos no pequeños. Una buena pista para ello es conocer lo que han hecho y dicho quienes han discutido, criticado y cuestionado, de hace ya bastante tiempo, los estereotipos de géneros dominantes en nuestras sociedades occidentales, por si nos sirviera de algo. Esta será nuestra última parada.

\footnotetext{
45 Evidentemente, unas 'políticas de identidad' que ya no pueden ser definidas de manera culturalista, sino de forma política o cívica.
} 


\section{Malestares de género y la tradición latina de la democracia}

Son los grupos sociales que no han formado parte de los estereotipos de género (Fdez-Llebrez, 2004, p. 23) (mujeres, homosexuales, lesbianas u otros) los que, junto a algunos de los cambios sociales y culturales acaecidos, han protagonizado las sucesivas crisis que han sufrido los estereotipos de género a lo largo de su historia, pese a su persistencia.

Si nos centramos en la época contemporánea, y en concreto a partir del siglo XIX, nos encontramos con que fueron movimientos sociales y políticos como el pro abolicionista o antiesclavista (que igualaba a negros con blancos — a lo no occidental con lo occidental-), o ciertos (y desiguales) procesos de integración social (judíos, gitanos,...), o las críticas al antisemitismo quienes denunciaron a los estereotipos de género por su carácter excluyente. Ni que decir tiene que el movimiento sufragista de las mujeres (que no por casualidad, en un principio, iba de la mano del pro abolicionista) (Sánchez, 2001, pp. 35-43) supuso un duro golpe al estereotipo femenino, y por extensión al masculino, al cuestionar las diferencias en cuanto al derecho de voto, lo que implicaba sacar del espacio privado a las mujeres otorgándoles un papel más activo, público y de igualdad que no quedaba recogido dentro del ideal masculino.

Pero no solo hubo críticas a tales estereotipos en estos grupos sociales. También ciertos procesos históricos y movimientos culturales ponían en solfa la quietud y serenidad de dichos estereotipos: la crisis espiritual sufrida tras la Primera Guerra Mundial, los tiempos convulsos del período de entre guerra, así como la crítica que conllevaban las vanguardias artísticas al ideal de belleza (cubismo, expresionismo, etc.), son algunos ejemplos que fueron erosionando los respectivos estereotipos de género.

No obstante, también hubo otros procesos sociales que afianzaron los estereotipos de género. Unos tuvieron influencia más indirecta, 
como los brotes nacionalistas, el fascismo y el nazismo, la propia experiencia soviética, la propia guerra mundial, etcétera. Pero también están los que tuvieron una relación más directa sobre los estereotipos de género, como la consolidación de la división del trabajo, la familia tradicional, el puritanismo, etcétera. Todos estos fueron, y algunos siguen siendo, factores que consolidaron los estereotipos masculinos y femeninos.

En tiempos más recientes, en particular desde los años sesenta en adelante, también estos estereotipos se han visto discutidos y problematizados. Lo que se conoce como la segunda ola del feminismo, aun con toda su pluralidad, lo que nos obliga a hablar de feminismos (Amorós \& De Miguel, 2005), supuso un claro menoscabo de muchos de los elementos que definen al ideal masculino: ${ }^{46}$ la crítica a la separación público versus privado; la reconsideración y, a la vez, problematización de la ética del cuidado; el cuestionamiento de la heterosexualidad obligatoria y la legitimidad del lesbianismo; la crítica a la consideración de que las mujeres tienen una sexualidad pasiva; la liberación sexual y la ruptura con la idea de nerviosismo; la denuncia de la violencia de género; el reconocimiento de la pluralidad de mujeres y su crítica a los modelos y la normativización (y normalización); o el cuestionamiento de que existe una esencia femenina, son algunos ejemplos de planteamientos que socavan el estereotipo femenino y, debido a su carácter relacional, también el masculino.

También los grupos gais ayudaron a este cometido rompiendo la identificación entre hombre y heterosexualidad, ampliando las formas de ser hombres, así como la exigencia de sus derechos. Los grupos de identidad de género que discuten la naturalización de los sexos y los géneros, y ciertos grupos de hombres (los denominados como antisexistas o pro feministas), ${ }^{47}$ que cuestionan los modelos de masculinidad imperantes y despliegan una actividad pública frente a la violencia de

46 Para el ideal masculino, ver Mosse (2000). No todo feminismo defiende lo que se dice a continuación, pero sí ciertas corrientes, aunque para algunas de las temáticas señaladas sí encontramos mayor unidad.

47 Para esta cuestión, acúdase a las reflexiones ya clásicas de Michael Kaufman, Michael 
género, son otros ejemplos de críticas hacia el estereotipo masculino y, por contagio, del femenino.

Pero, como ocurrió antaño, también hubo cambios, movimientos culturales más amplios, que trastocaron dichos estereotipos. Seguramente el movimiento juvenil de los años sesenta y setenta sea el caso más notorio; la contradictoria generación beat, que no hacía gala de su hombría y apostaba por relaciones sexuales tanto con mujeres como con hombres; o la música popular, encabezada por grupos como The Beatles, que cambiaron la estética, o los múltiples grupos de rock que pluralizaron mucho la realidad vital y personal; o grupos como los hippies, los punkies u otros, e, incluso, los cambios acaecidos en la publicidad son algunas muestras prácticas de esto. Ejemplos que ponían en cuestión los ideales masculinos y femeninos por su variada y múltiple forma de celebrar e incorporar el intrusismo en nuestras vidas. Un trastoque que, incluso, se llegó a ver, como no podía ser menos, como un momento de declive y pánico moral (Weeks, 1993, pp. 66-103).

Del mismo modo, la creencia de que vivimos un cambio de época que descoloca ciertas normatividades pone en solfa elementos característicos de los estereotipos; o el reconocimiento de las sociedades multiculturales, y más la interculturalidad, a partir del fenómeno migratorio en Europa, vuelve a traer fantasmas occidentales en donde siguen operando actitudes masculinas y femeninas estereotipadas.

No obstante, y como también ocurriera antes de la Segunda Guerra Mundial, había y hay factores que siguen apuntalando y afianzando los estereotipos de género. Las crisis económicas (que reafirman la división del trabajo); la reacción moral conservadora (de la que forman parte ciertos grupos de hombres que ven una pérdida de poder masculino y postulan la recuperación de la perdida esencia masculina); ${ }^{48}$

Kimmel o Daniel Welzer-Lang. Ver Brod \& Kaufman (1994), Welzer-Lang (2001) y Kimmel, Hearn \& Connell (2004), entre otros.

48 Para este enfoque netamente conservador, ver el clásico Bly (1992), que da cobertura a todo el movimiento mitopoiético que lo acompaña. 
algunas facetas militarizantes de los propios años sesenta y setenta; la exclusión de los inmigrantes, identificados como lo diferente; la legitimación de los malos tratos y de la violencia a la hora de resolver conflictos interpersonales; la aceptación superficial del feminismo; las reticencias hacia los gais y las lesbianas; y otros tantos factores, son la otra cara de la moneda. Por lo tanto, como se aprecia, los estereotipos de género no solo son normatividades cambiantes y sujetas a desgaste, sino que además forman parte de las sociedades, quedando insertos en los cambios y persistencias que también acontecen en ellas. ${ }^{49}$

Si bien todo este recorrido nos muestra una realidad diversa, también lo es que se pueden encontrar ciertos planteamientos comunes que atraviesan al conjunto, o a la mayoría, de las críticas que se le han realizado a los estereotipos de género. De forma resumida, estos planteamientos comunes los podríamos agrupar en dos ideas motrices.

Por un lado, aquellas que supusieron, y suponen, una crítica a las relaciones de poder que vertebran las relaciones entre los géneros y las opciones sexuales. Un elemento que es central para cualquier teoría democrática, ya lo expresen los propios sujetos implicados o lo hagan otros por razones de solidaridad y justicia para con ellos y ellas.

Por otro lado, se encuentran aquellas ideas que expresan un profundo malestar con algunos de los elementos — los más característicos- que definen la identidad de un grupo. Por ejemplo, el cuestionamiento de la separación público/privado y la exigencia de que las mujeres sean también valoradas en el ámbito público expresa un claro malestar con lo designado como ética del cuidado.$^{50} \mathrm{Y}$ no porque esta no contenga cosas positivas, que las tiene, sino porque también conlleva dolores, sinsabores nada despreciables para las mujeres que terminan generando daño. La exigencia a las mujeres de tener que estar siempre

\footnotetext{
49 Para un planteamiento similar, ver Fraser (2008, pp. 31-64).

50 La ética del cuidado está relacionada con lo que se conoce como el yo en relación. Este lo puso en circulación Jean Baker Miller (1973), siendo preciso verlo en contraste con lo que se denomina como yo en los logros. Para un desarrollo y actualización del significado del yo en relación, ver Bleichmar (1991, pp. 85 y ss.).
} 
pendiente del otro no es una experiencia muy satisfactoria que se diga y que poca gente aguanta cómodamente. Este es un ejemplo de cómo situaciones que generan disgustos y dolores en las mujeres se convierten en malestares feministas hacia dicha normativización; malestares que conllevan una exigencia de autodesignación (autodeterminación) democrática, libre e igualitaria para las mujeres digna de encomio.

Por lo tanto, si analizamos esas experiencias - por lo menos algunas de ellas, las más profundas - , vemos que ha habido una crítica a las desiguales relaciones de poder, pero también un inconformismo ante ciertos sinsabores, ante ciertas dolencias sexistas que se transformaron en malestar(es) ante su propia situación y las causas que la generaron y generan. Una reconsideración crítica que nos muestra, además, que quienes se salen de dichas asignaciones y reglamentaciones terminan ganando más de lo que pierden (pese a lo duro que pueda ser el proceso). ${ }^{51}$

Todos estos movimientos son ejemplos de cómo la historia cambia. En este caso, fueron y son cambios que abrieron brecha en pro de la igualdad y la libertad. De hecho, hoy vivimos un tiempo de crisis e impasse nada despreciable (Seidler, 2007). Pero también es verdad que la crisis de los estereotipos es más el resultado de una considerable erosión que el de un cuestionamiento por confrontación, de ahí su persistencia. Es decir, los estereotipos de género están en crisis (y más en las mujeres que en los hombres), pero aún siguen vivos (Garaizabal \& Fdez-Llebrez, 2010, pp. 133-197).

Tal y como hemos dicho, la erosión de los estereotipos ha estado protagonizada (aunque no en exclusividad) por aquellos grupos y personas que han quedado fuera de ellos. Pero los estereotipos de género no afectan solo a quienes fueron y son excluidos, sino que repercuten sobre el conjunto de las relaciones de género y sobre las formas

\footnotetext{
51 No está de más reconocer que, en lo que acabamos de decir, una parte importante de las mujeres, y algunos hombres, llevan cierta ventaja a una parte considerable del conjunto de los hombres. Y, también, que no estaría mal que los hombres diéramos más pasos ya en esta dirección.
} 
de conceptualizar dichas identidades. De ahí que podamos afirmar que los problemas que contienen el desarrollo de los estereotipos de género, y su crítica, son cuestiones que nos afectan a todos y todas.

No solo el ideal masculino y femenino, en estado puro, son casi imposibles de alcanzar (Fdez-Llebrez, 2004, p. 37), sino que hay razones para pensar que la mera existencia de los propios estereotipos de género también puede generar dolor en (ciertos) hombres y mujeres, siendo posible hablar de la existencia de sinsabores y/o dolores de género. Esto es frecuentemente reconocido en lo que atañe a las mujeres, pero lo que se está planteando aquí es que también, aunque de forma distinta — pues está atravesada por una desigual relación entre los géneros-, estos dolores afectan, o pueden afectar, a los hombres.

En concreto, si miramos la realidad de los hombres, comprobamos cómo los diferentes atributos que definen la masculinidad tradicional generan ciertos privilegios, pero también son fuente de dolor tanto propio como, sobre todo, ajeno. El control emocional, la obsesión por el éxito y los logros, la búsqueda del control y de la perfección, el deseo de omnipotencia y de autoexigencia, el poco cuidado hacia los demás y uno mismo (sobre todo desde el punto de vista emocional), el control a la hora de demostrar los afectos entre hombres (siempre que no se esté ebrio o en medio de un partido de fútbol) o la debilidad íntima de las amistades entre chicos son algunos sinsabores que, junto a cuestiones injustas, como la violencia contra las mujeres, el desigual reparto de las tareas domésticas o la ausencia de padres en la coeducación de los hijos e hijas (entre otras), diseñan un panorama poco alentador desde el punto de vista humano, tanto social como personal, para los hombres. ${ }^{52}$

Es cierto que estos posibles sinsabores pueden convertirse en un impulso para la reproducción individual y social, para la "aceptación, afirmación, celebración y propagación del poder individual y colectivo

\footnotetext{
52 Para la cuestión de la igualdad, ver González (2010). Para el aspecto identitario: Garaizabal \& Fdez-Llebrez (2010).
} 
de los hombres" (Kaufman, s. f., p. 6). ${ }^{53}$ Pero, como señala Kaufman, también "pueden servir de impulso para el cambio" (p. 6), aunque, para ello, es preciso convertir dicho dolor en malestar para con el estereotipo masculino y femenino, defendiendo relaciones igualitarias y de respeto entre los géneros y los sexos (igualdad para las mujeres y para las diferentes opciones sexuales), así como la libertad para configurar nuestras identidades sexuales y de género más allá de los estereotipos existentes.

Y es aquí en donde la reflexión anterior sobre las identidades y su configuración cobra sentido, pues será partiendo de las identidades como un continuum como podremos romper las barreras que solidifican los estereotipos. De lo contrario, la sima y el vacío será la única alternativa ante la crisis de las identidades. Una sima que se preferirá no pisar, por el peligro que conlleva, por lo que se terminarán cosificando, de nuevo, las identidades hoy problematizadas. De ahí la importancia democrática de incorporar dicha cuestión a la lucha contra la discriminación por razón de sexo.

Este cambio, cuanto menos, supone hacer justicia para con las mujeres y con aquellos que han sido estigmatizados (transexuales, gais, lesbianas, etc.). Una justicia reparadora que no puede ser obviada en las democracias del siglo XXI en las que vivimos y sobre la que la teoría política tiene mucho que decir. Es verdad que la teoría política en singular no existe, habiendo una pluralidad de formas de abordar estos cambios. Pero también lo es que no puede valer cualquier teoría política, porque podría significar una vuelta al mismo punto de partida. Ahondar en estos malestares supone desarrollar una forma distinta de pensarnos a nosotros mismos, de ahí que requiramos desplegar una mirada y una música capaz de acoger tales cambios. Una música que, tal y como hemos visto, afecta a la cuestión de las identidades de género y sexual. Pero también a la propia idiosincrasia de la teoría política.

53 La versión original puede consultarse en www.michaelkaufman.com 
Y es aquí donde se torna oportuno tirar del hilo abandonado del bumanismo cívico y de la tradición latina de la democracia, ${ }^{54}$ pues ahí se encuentran muchas claves teóricas y prácticas para el gobierno de los ciudadanos que nos permiten transformar tales malestares en bienestares para hombres, mujeres, transexuales,... Y, para ello, es crucial retomar una concepción de la identidad donde los estereotipos de género y sexual no quepan (o encajen mal). Unas identidades que, aprendiendo de la experiencia transexual y transgenérica, se caractericen por desplegar un continuum entre hombres y mujeres que nos permita revertir y romper los dogmatismos de género existentes. Dogmatismos que de forma acuciante sufren los y las transexuales, y más aún los y las que no se quieren operar, pero también -aunque de manera diferente y desigual- aquellos hombres y mujeres que no quieren reproducir los estereotipos de género imperantes.

\section{Referencias}

Almond, G., \& Verba, S. (1963). The civic culture. New Jersey: Princeton University Press.

Alonso, V. (2010). Retórica, democracia y crisis. Un estudio de teoría política. Madrid: Centro de Estudios Constitucionales.

Amorós, C., \& De Miguel, A. (Eds.). (2005). Teoría feminista: de la Ilustración a la globalización. De los debates sobre el género al multiculturalismo (3). Madrid: Minerva.

Austin, J. L. (1991). Cómo hacer cosas con palabras. Barcelona: Paidós.

Baker Miller, J. (1973). Psychoanalysis and women. New York: Brunner/Mazel. Benhabib, S. (1990). El otro generalizado y el otro concreto: la controversia Kohlberg-Gilligan y la teoría feminista. En S. Benhabib \& D. Cornell, Teoría feminista y teoría crítica. Valencia: Alfons el Magnánim, Benhabib, S. (2006a). El sery el otro en la ética contemporánea. Barcelona: Gedisa. Benhabib, S. (2006b). Las reivindicaciones de la cultura. Igualdady diversidad en la era global. Buenos Aires: Katz.

Bleichmar, E. D. (1991). La depresión en la mujer. Madrid: Temas de Hoy. Bly, R. (1992). Iron John. Madrid: Plaza y Janés.

54 Para esta cuestión: Roiz (2003 y 2008). 
Brod, H., \& Kaufman, M. (Eds.). (1994). Theorizing masculinities. Thousand Oaks: Seage Publications.

Butler, J. (1999). Gender trouble: feminism and the subversion of identity. New York: Routledge.

Calvo Martínez, T. (2011). Presentación. En Aristóteles, Metafísica. Madrid: Gredos.

Carrillo, R., \& Saibacam, J. (2010). El mundo interno, el imaginario y la política. Foro Interno. Anuario de Teoría Política, (10).

Dahl, R. (1992). La democracia y sus críticos. Barcelona: Paidós.

Daly, M. (1978). Gyn/ ecology. Boston: Beacon Press.

Davidoff, L., \& Hall, C. (1994). Fortunas familiares. Hombres y mujeres de la clase media inglesa (1780-1850). Madrid: Cátedra.

De Beauvoir, S. (1999). El segundo sexo. Madrid: Cátedra.

Delphy, C. (1993). Rethinking sex and gender. Women's Studies Int. Forum, 16(1).

Descartes, R. (1983). El discurso del método. Madrid: Alianza.

Dover, K. (1986). Greek homosexuality. Cambridge: Harvard University Press.

Downs, A. (1967). An economic theory of democracy. New York: Harper and Row.

Dworkin, A. (1983). Right-wing women. New York: Perigee Books.

Engelken-Jorge, M. (2010). Pasiones, identidades colectivas y deliberación: los retos planteados por la democracia agonística. Foro Interno. Anuario de Teoría Politica, (10).

Fdez-Llebrez, F. (2001). Pensamiento trágico y ciudadanía compleja: crítica a la razón omnipotente. Foro Interno. Anuario de Teoría Política, (1).

Fdez-Llebrez, F. (2004). ¿Hombres de verdad? Estereotipo masculino, relaciones entre los géneros y ciudadanía. Foro Interno. Anuario de Teoría Politica, (4).

Fdez-Llebrez, F. (2008). Pensamiento retórico y masculinidades: de la dicotomía al continuum. Utopia y Praxis Latinoamericana, (43).

Fdez-Llebrez, F. (2009). El humanismo cívico como vector de la calidad democrática. En J. Montabes \& R. Ojeda (Coords.), Estudios de ciencia politica y de la administración. Valencia: Tirant lo Blanch.

Fdez-Llebrez, F. (mayo, 2014). La democracia y sus críticas. Ponencia presentada en el Seminario La Democracia a Debate, Granada, España.

Fichte, J. G. (1994). Fundamento del derecho natural según los principios de la doctrina de la ciencia. Madrid: Centro de Estudios Constitucionales.

Foucault, M. (1992). Historia de la sexualidad. Madrid: Siglo XXI. 
Fraser, N. (2000). ¿De la redistribución al reconocimiento? Dilemas de la justicia en la era postsocialista. New Left Review, (0).

Fraser, N. (2008). Escalas de justicia. Barcelona: Herder.

Fuss, D. (1990). Teoría gay y lesbiana: el tema de las políticas de identidad. Madrid: manuscrito no publicado.

Garaizabal, C. (1998). La transgresión del género. Transexualidades un reto apasionante. En Nieto, Transexualidad, transgenerismo y cultura.

Garaizabal, C., \& Fdez-Llebrez, F. (2010). Cambios y persistencias en la construcción de las identidades de género. En M. A. Caro \& F. FdezLlebrez (Coords.), Buenos tratos.

González, B. (2010). Ganando en igualdad, gana toda la sociedad. Algunos retos en un contexto de cambio social. En M. A. Caro \& F. FdezLlebrez (Coords.), Buenos tratos.

Gutmann, A. (2008). La identidad en democracia. Madrid: Katz.

Haraway, D. (1995). Ciencia, cyborg y mujeres. Madrid: Cátedra, Feminismos.

Hull, G. T., Scott, P. B., \& Smith, B. (Eds.). (1982). All the women are white, all the blacks are men, but some of us are breve: black women's studies. Old Westbury New York: Feminist Press.

Inglehart, R., \& Welzel, C. (2006). Modernización, cambio culturaly democracia: la secuencia del desarrollo bumano. Madrid: Centro de Investigaciones Sociológicas.

Irigaray, L. (1992). Yo, tú, nosotras. Madrid: Cátedra.

Irigaray, L. (2009). Ese sexo que no es uno. Madrid: Akal.

Kaufman, M. (s. f.). La construcción del movimiento masculino dirigido a terminar con la violencia contra las mujeres. Ponencia presentada en el Programa para la Igualdad de Género en el Sudeste de Asia, Canadá. Recuperado de www.hombresigualdad.com/emak.construccionmm-kaufman (versión original: www.michaelkaufman.com).

Kimmel, M., Hearn, J., \& Connell, R. (Eds.). (2004). Handbook of studies on men and masculinities. London: Sage Publications.

Laqueur, T. (1994). La construcción del sexo. Cuerpo y género desde los griegos hasta Freud. Madrid: Cátedra.

Lorde, A. (2003). La hermana, la extranjera: artículos y conferencias. Madrid: Horas y Horas.

Morin, E. (1994). Introducción al pensamiento complejo. Barcelona: Gedisa.

Mosse, G. L. (2000). La imagen del hombre. La creación de la moderna masculinidad. Madrid: Talasa. 
Mouffe, Ch. (2003). La paradoja democrática. Barcelona: Gedisa.

Nieto, J. A. (1998). Transgénero/transexualidad: de la crisis a la reafirmación del deseo. En J. A. Nieto (Comp.), Transexualidad, transgenerismo y cultura. Nieto, J. A. (2008). Transexualidad, intersexualidady dualidad de género. Barcelona: Ediciones Bellaterra.

Nieto, J. A. (Comp.). (1998). Transexualidad, transgenerismo y cultura. Antropología, identidad y género. Madrid: Talasa.

Nussbaum, M. (2005). El cultivo de la humanidad. Una defensa clásica de la reforma de la educación liberal. Barcelona: Paidós.

Nussbaum, M. (2006). Las fronteras de la justicia. Consideraciones sobre la exclusión. Barcelona: Paidós.

Osborne, R. (1993). La construcción sexual de la realidad. Madrid: Cátedra.

Pérez Ledesma, M., \& Sierra, M. (Eds.). (2010). Culturas políticas: teoría e identidad. Zaragoza: CSIC.

Roiz, J. (1980). Introducción a la ciencia politica. Barcelona: Vicens Universidad.

Roiz, J. (2003). La recuperación del buen juicio. Teoría politica en el siglo veinte. Madrid: Editorial Foro Interno.

Roiz, J. (2008). Sociedad vigilante y mundo judio en la concepción del Estado. Madrid: Editorial Complutense.

Roiz, J. (2013). El mundo interno y la política. Madrid: Plaza y Valdés.

Rubin, G. (1989). Reflexionando sobre el sexo: notas para una teoría radical de la sexualidad. En C. Vance (Comp.), Placer y peligro. Madrid: Editorial Revolución.

Ryle, G. (2005). El concepto de lo mental. Barcelona: Paidós.

Sánchez, C. (2001). Genealogía de la vindicación. En E. Beltrán \& V. Maqueira (Eds.), Feminismos. Debates teóricos contemporáneos. Madrid: Alianza.

Schumpeter, J. (1984). Capitalismo, socialismo y democracia. Barcelona: Folio.

Sedgwick, E. K. (1998). Epistemología del armario. Barcelona: Ediciones de la Tempestad.

Seidler, V. (2007). Masculinidades. Culturas globales y vidas intimas. Barcelona: Montesinos.

Skinner, Q. (1993). Fundamentos del pensamiento político moderno. 2 vols. México: FCE.

Soley-Beltrán, P. (2009). Transexualidady la matriz heterosexual: un estudio crítico de Judith Butler. Barcelona: Ediciones Bellaterra.

Tarrow, S. et al. (2005). Dinámica de la contienda política. Barcelona: Hacer. Tilly, Ch. (2007). Democracia. Madrid: Akal. 
Uría, P. (2009). El feminismo que no llegó al poder. Trayectoria de un feminismo crítico. Madrid: Talasa.

Weeks, J. (1993). El malestar de la sexualidad. Significados, mitos y sexualidades modernas. Madrid: Talasa.

Weeks, J. (2001). ¿Héroes caídos? Todo sobre los hombres. En AA. VV., Héroes caídos. Masculinidad y representación. Valencia: Generalitat Valenciana.

Welzer-Lang, D. (2001). Iniciativas europeas y análisis de las resistencias masculinas a los cambios. Recuperado de http://www.jerez.es/fileadmin/Documentos/hombresxigualdad/fondo_documental/Identidad_masculina/Iniciativas_europeas_y_nalisis_de_las_resistencias_mascullinas_al_cambio.pdf

Wolin, S. S. (1974). Politica y perspectiva. Buenos Aires: Amorrortu.

Wolin, S. S. (2008a). Democracy incorporated. Managed democracy and the specter of inverted totalitarianism. Princeton: Princeton University Press.

Wolin, S. S. (2008b). Democracia S. A. La democracia dirigida y el fantasma del totalitarismo invertido. Buenos Aires: Katz.

Wollstonecraft, M. (1994). Vindicación de los derechos de la mujer. Madrid: Cátedra.

Young, I. M. (1996). Vida política y diferencia de grupo: una crítica del ideal de ciudadanía universal. En C. Castells (Comp.), Perspectivas feministas en teoría política. Barcelona: Paidós. 
